\title{
Nanofiltration fractionation of radioactive solution components as a method for reducing the volume of wastes intended for permanent disposal ${ }^{*}$
}

\author{
Aleksandr S. Chugunov ${ }^{1}$, Vadim A. Vinnitskii ${ }^{1}$ \\ 1 Saint Petersburg State Institute of Technology (Technical University) 26, Moskovsky Prospect, St. Petersburg, 190013, Russia \\ Corresponding author: Aleksandr S.Chugunov(tchugunov@mail.ru)
}

Academic editor: Yury Kazansky • Received 7 March 2019 • Accepted 27 April 2019 • Published 17 May 2019

Citation: Chugunov AS, Vinnitskii VA (2019) Nanofiltration fractionation of radioactive solution components as a method for reducing the volume of wastes intended for permanent disposal. Nuclear Energy and Technology 5(2): 123-128. https://doi. org/10.3897/nucet.5.35801

\begin{abstract}
Baromembrane purification methods as part of liquid radioactive media processing complexes are increasingly included in the practice of radioactive waste management. The paper presents the results of a comparative study of the performance of commercially available hyper- and nanofiltration elements when a simulated solution is continuously phosphatized. The study revealed the influence of changes in the feed solution salinity on the permeability, working pressure in the brine chamber of the hyper- and nanofiltration apparatus and the permeate salinity. It is shown that, in a closed loop of liquid radioactive waste, the introduction of polyphosphates to stabilize the truly dissolved forms of multivalent metals on the ULP reverse-osmotic membrane leads, as expected, to a systematic performance degradation, first of all, in the membrane permeability at a fixed pressure in the apparatus. The permeate of the system with a nanofiltration membrane, VNF (Vontron NanoFiltration), contains a sufficiently high salt concentration indicating that sodium salts formed during complexation are removed from the circuit, thereby reducing the solution osmotic pressure which critically affects the yield of the purified solution. Thus, nanofiltration in combination with chelating agents can be an effective tool for fractionating components of radioactive solutions, ensuring the achievement of standard indicators for wastewater and biologically hazardous substances that are subject to permanent disposal.
\end{abstract}

\section{Keywords}

Radioactive waste, nanofiltration, complexation, osmotic pressure, reverse osmosis, membrane permeability

\section{Introduction}

A high degree of stability in operation at the lowest possible mass/dimensional characteristics and volumes of radioactive waste subject to permanent disposal is a mat- ter-of-course requirement imposed on systems for processing liquid radioactive media. To the greatest extent, this criterion is met by continuous action systems based on precipitation techniques and hyperfiltration. 
Methods based on precipitation of controlled impurities in the form of poorly soluble compounds have the highest selectivity but, at the same time, the most complicated organization.

Hyperfiltration, which is considered to be quite an effective method for reducing the volume of radioactive waste of complex and irregular compositions subject to controlled storage or conditioning (Vasilenko et al. 2005, Ryabchikov 2008, Ambashta and Sillanpaa 2012, Zakrzewska-Trznadel et al. 2001, Pabby 2008), has a number of downsides in terms of structuring the processes under consideration, including:

- an increased volume of waste subject to permanent disposal due to the inclusion in their composition of environmentally friendly substances: hydrocarbons, chlorides and sulfates of sodium, potassium, magnesium and calcium, which can be legally introduced into the regional hydrographic network; and

- limited permissible brine salinity for the target components due to the need to maintain the process driving force proportional to the difference between the pump head and osmotic pressure determined by the total ion concentration.

Using processing techniques for separating the components of solutions to be processed according to the degree of biological hazard and environmental impact, it is possible to increase the operational stability of the entire system by distributing substances over the cleaning stages and solve the following main tasks of industrial water supply:

- recycling of the main bulk of water;

- removal from the production process of the bulk of technogenic pollution represented primarily by alkali metal salts used or formed in technological processes;

- localization and concentration of biologically hazardous components represented in most cases by salts of non-ferrous metals and activated corrosion products with subsequent removal of the resulting solutions for processing by precipitation methods; and

- increased filling of ${ }^{134,137} \mathrm{Cs}$ sorbents by reducing the competition for sorption sites from the side of polyvalent cations.

The use of nanofiltration elements seems to be the most promising for fractionating technogenic water components into groups with similar chemical properties. Unlike hyperfiltration (reverse osmosis) membranes, the selectivity of nanofiltration membranes is determined by the properties of salts contained in the solution: minimum (40-70\%) for salts of alkali metals and maximum (90-95\%) for salts of polyvalent metals (Arzhanova et al. 2010) with a rather rigid hydration shell inherent in them. In fact, these membranes can be considered as a kind of "molecular sieves" capable of sorting the components by the molecule size.

Even $95 \%$ selectivity means a guaranteed transition of a part of ions of polyvalent metals, including activated prod- ucts of corrosion and fission, to the permeate. Therefore, it seems reasonable to exclude the very probability of their transfer due to a sharp increase in the size of molecules, including ions of polyvalent metals, which can be realized by forming their complexes with large-sized ligands.

The aim of the work was to conduct a comparative study of the efficiency of technologies for processing radioactively contaminated solutions based on commercially available hyper- and nanofiltration apparatus, under conditions where the transfer of polyvalent metals providing a form of radioactive waste acceptable for permanent disposal is completely eliminated and the bulk of technologically and radioactively contaminated water is involved in industrial circulation.

\section{Experimental procedure}

Experiments were conducted on the facility, a schematic diagram of which is shown in Fig. 1. The system is made of three units capable of operating in standalone mode.

The first processing stage involved an SL-10' fibrous polypropylene microfilter with the declared pore size of $1.0 \mu \mathrm{m}$, a salt dissolver for dosing the complexone, and a Vontron series 1812-100 hyperfiltration element. Tap water of the St. Petersburg network was used as a feed solution supplied to the microfilter inlet with a permissible pressure of $0.32 \pm 0.02 \mathrm{MPa}$ for the element stable operation in low-pressure hyperfiltration mode. The permeate was collected in the feed tank of the final stage, and the concentrate in the intermediate tank equipped with an

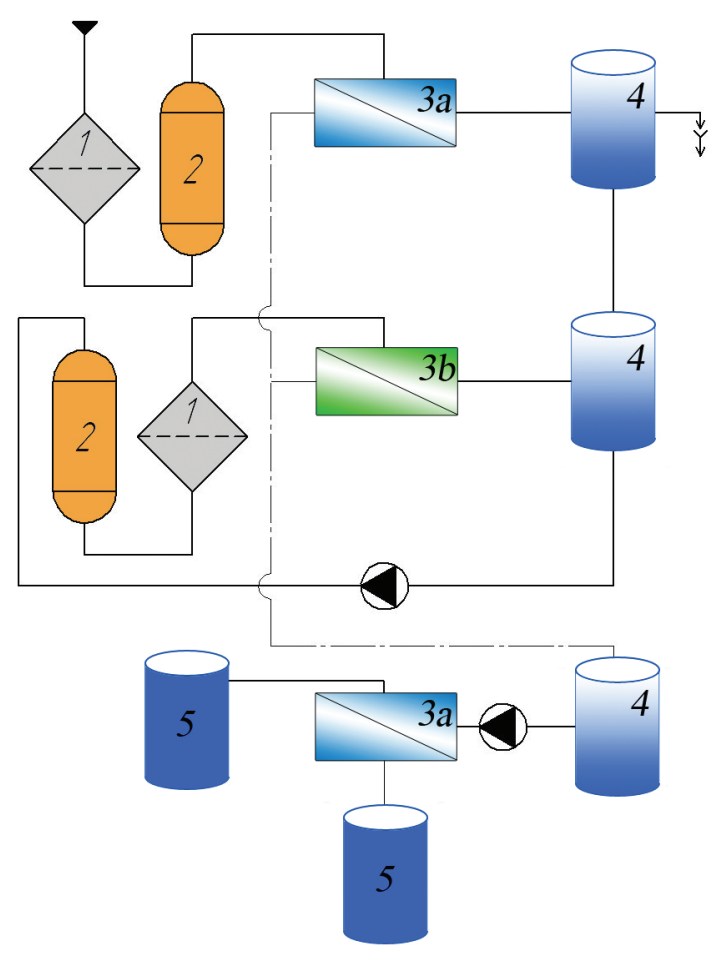

Figure 1. Schematic diagram of the facility: 1 - microfilter; 2 salt dissolver $3 \mathrm{a}$ - hyperfiltration apparatus; $3 \mathrm{~b}$ - hyperfiltration (nanofiltration) apparatus; 4 -intermediate tank; 5-control tank. 
overflow device to maintain a constant level of the feed solution, from where it was transferred by gravity to the feed tank of the second stage.

The second stage was a circuit for concentrating biologically hazardous components, including:

- a receiving-feeding tank;

- a feeding membrane DLX pump with a capacity of $15 \mathrm{dm}^{3} / \mathrm{h}$ at a pressure up to $0.55 \mathrm{MPa}$;

- a salt dissolver for continuous dosing of ligands; and

- a microfilter to protect the membrane surface from potential mechanical effects of dispersed particles formed in the process.

For comparative studies at the second processing stage, structurally identical "Vontron" 1812-50 membrane elements with a membrane surface of $0.32 \mathrm{~m}^{2}$ were used, namely, hyperfiltration ULP and nanofiltration VNF.

The permeate at this step was discharged into the receiving tank of the final stage, ensuring the production of pure water for internal requirements and the concentrate discharged as waste water. The separating element was the "Vontron" 1812-50 hyperfiltration element.

The ratios of permeate and concentrate flows and the working pressure in the purge chamber were provided by drainage controllers with the required flow rate. At the second cleaning stage, an overflow valve is additionally installed with a response pressure of $0.5 \mathrm{MPa}$, which protects the feeding pump from overloading.

Changes in total salt concentrations in the flows were promptly monitored by conductometric salinometers (DM1 Dual In-line TDS Meters).

To control the total hardness and concentration of the permeate components, well-known methods were used (Lurie 1973): trilonometry for calcium ions and photocolorimety for ions of non-ferrous metals, with preliminary ion-exchange concentration on the Dowex 50WX8 hydrogen-form cation resin.

\section{Results and discussion}

Table 1 shows the averaged quality indicators of the water of the St. Petersburg water supply system used in the experiments and the feed solution obtained from it for the second processing stage. It should be noted that, according to the concentrations of non-ferrous metal ions detected in this solution, only iron compounds fit into the water quality standards established for fishery water bodies. Thus, even for the discharge of these low-mineralized waters from the production cycle, engineering measures are already required to correct their mineral composition.

Theoretically, hyperfiltration from technogenic waters with such salinity makes it possible to extract $\sim 95-98 \%$ of sufficiently pure water that is easily conditioned to almost any required standards. However, in the process of flow-through concentration, there is a high probability of spontaneous release of oxyhydrates, first of all Fe(III), and carbonates of alkaline-earth and non-ferrous metals
Table 1. Indicators of the solution in the circulation circuit during the transition to stationary mode.

\begin{tabular}{lcc}
\hline \multicolumn{1}{c}{ Indicator } & System water & $\begin{array}{c}\text { Second step feed } \\
\text { solution }\end{array}$ \\
\hline $\mathrm{TDS}-\mathrm{meter}$ salt content, $\mathrm{mg} / \mathrm{dm}^{3}$ & 31 & 72 \\
$\mathrm{pH}$ & 6.85 & 6.82 \\
$\mathrm{Na}^{+}, \mathrm{mg} / \mathrm{dm}^{3}$ & 7 & 14 \\
Total alkalinity, $\mathrm{mEq} / \mathrm{dm}^{3}$ & 0.85 & 2.2 \\
Total hardness, $\mathrm{mEq} / \mathrm{dm}^{3}$ & 0.68 & 1.75 \\
$\mathrm{Ca}^{2+}, \mathrm{mg} / \mathrm{dm}^{3}$ & 12 & 25 \\
$\mathrm{Mn}^{2+}, \mathrm{mg} / \mathrm{dm}^{3}$ & 0.09 & 0.24 \\
$\mathrm{Fe}^{\mathrm{III}}+\mathrm{Fe}(\mathrm{III}), \mathrm{mg} / \mathrm{dm}^{3}$ & 0.25 & 0.11 \\
$\mathrm{Co}^{2+}, \mathrm{mg} / \mathrm{dm}^{3}$ & $\mathrm{BLD}$ & $\mathrm{BLD}$ \\
$\mathrm{Ni}^{2+}, \mathrm{mg} / \mathrm{dm}^{3}$ & $\mathrm{BLD}$ & 0.03 \\
$\mathrm{Cu}^{2+}, \mathrm{mg} / \mathrm{dm}^{3}$ & $\mathrm{BLD}$ & 0.02 \\
$\mathrm{Zn}^{2+}, \mathrm{mg} / \mathrm{dm}^{3}$ & $\mathrm{BLD}$ & $\mathrm{BLD}$ \\
$\mathrm{Cl}^{-}, \mathrm{mg} / \mathrm{dm}^{3}$ & 17 & 16 \\
$\mathrm{NO}_{3}^{-}, \mathrm{mg} / \mathrm{dm}^{3}$ & 0.4 & 1.4 \\
\hline
\end{tabular}

Note: BLD - Below limit of detection

within the apparatus and on the membrane surfaces. It should be noted that these metals are carriers, with which their radioactive chemical analogues are released, i.e., activated corrosion products (first of all ${ }^{60} \mathrm{Co}$ ) and some fission products $\left({ }^{90} \mathrm{Sr}\right)$. This decreases the permissible reduction of radioactive solutions processed.

Nanofiltration elements as a kind of "molecular sieves" have a significantly lower selectivity for simple ionic salt forms than hyperfiltration membranes. This makes it possible to separate the components present in the solution and control the process by changing the size of the molecules when various complex forms with polyvalent cations are generated. This can be ensured through the use of complexones. It should be noted that the use of organic complexones, such as EDTA ions, has a number of negative aspects. For example, the relatively high solubility of these compounds (Nikitin et al. 1963) complicates their removal from process media to ensure the acceptance criteria for radioactive waste to be disposed (NR-093-14 20159). In terms of the price/effect ratio (Zhdanov 1979), the most acceptable method for increasing the nanofiltration selectivity is the formation of chelate-like structures by polyvalent metal ions with polyphosphates (Table 2 ).

Conversion of polyphosphates into practically insoluble orthophosphates fully compatible with cement matrices can be carried out, if necessary, by thermohydrolysis

Table 2. Stability constants $\left(\lg K_{\text {stab }}\right)$ of complex forms of some linear polyphosphates with alkaline-earth and non-ferrous cations (Zhdanov 1979).

\begin{tabular}{lccc}
\hline $\begin{array}{c}\text { Central } \\
\text { atom }\end{array}$ & Pyrophosphate- & $\begin{array}{c}\text { Ligands } \\
\text { Tripolyphosphate- }\end{array}$ & Tetrapolyphosphate- \\
\hline $\mathrm{Mg}^{2+}$ & 7.2 & 8.6 & 6.04 \\
$\mathrm{Ca}^{2+}$ & 6.8 & 8.1 & 5.46 \\
$\mathrm{Mn}^{2+}$ & & 7.15 & \\
$\mathrm{Co}^{2+}$ & 6.1 & 6.94 & \\
$\mathrm{Ni}^{2+}$ & 5.94 & 6.75 & 9.44 \\
$\mathrm{Cu}^{2+}$ & 7.6 & 8.3 & \\
$\mathrm{Zn}^{2+}$ & 8.7 & 7.5 & \\
\hline
\end{tabular}


while, for the destruction of organic phosphates, it will be necessary to use rather complex and expensive systems of oxidative hydrolysis, for example, proposed for processing accumulated waste bottoms at nuclear power plants.

As Figure 2 shows, such sufficiently high values of the constants provide an almost complete conversion of all metal ions into chelate complex forms already at an almost stoichiometric amount of ligands.

Dosing of complexing substances (the so-called antiscalants) is widely used as a method for preventing the formation of deposits in hyperfiltration technologies for obtaining pure water.

For phosphating the solution at this stage, polyphosphate loading for household water softeners BF (TU 3697-023-48981941-2014) was used, the low dissolution rate of which allowed the use of simple ligand dispensers, i.e., salt dissolvers, thus increasing the entire system reliability.

Another advantage to be considered when using these compounds for processing technogenic waters is that the products of their hydrolysis are orthophosphate ions that, with $\mathrm{Ca}^{2+}$ and d-metal cations, form poorly soluble salts compatible with all mineral binders recommended for conditioning radioactive wastes. It is advisable to use lime "milk" as an alkaline agent and industrially manufactured equipment, for example, apparatus with a "jacket" and a mixing device.

Therefore, the most promising membrane methods for processing technologically and radioactively contaminated waters are systems with recycled feed solutions that make it possible as follows:

- to reduce the number of installed baromembrane devices;

- to stabilize soluble forms by binding polyvalent metal ions into stable complex compounds, ensuring the possibility of achieving a high degree of supersaturation of the solution during the permeate discharge;

- to ensure that crystalline double salts are extracted from the supersaturated solution;

- to remove the concentration polarization and reduce the probability of forming deposits due to a high solution rate maintained in the brine chamber; and

- to effectively protect the membrane working layer against abrasion by dispersed particles using preliminary micro- or ultrafiltration.

Since the permeability of the salt-holding membranes and the quality of the filtrate is determined by the difference between the osmotic pressure $\pi$ calculated by the Van Hoff equation

$$
\pi=R T \sum_{i} C_{i}
$$

(where $R$ is the universal gas constant; $T$ is the thermodynamic temperature of the solution; $C_{i}$ is the concentration of osmotically active particles, $\mathrm{mol} / \mathrm{dm}^{3}$ ) and working pressure in the concentration chamber, it is logical to use the TDS meter readings as an argument. It is clear that the value measured by these instruments cannot be directly

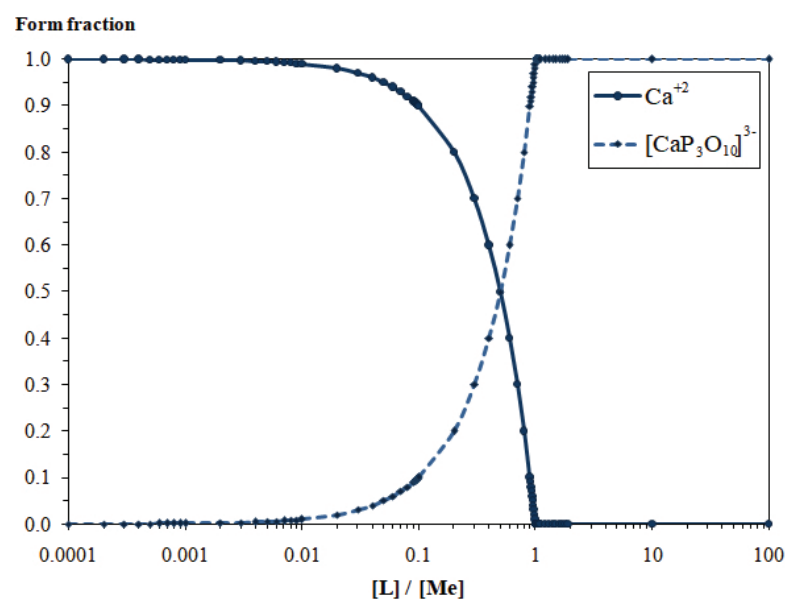

Figure 2. Distribution of complex calcium tripolyphosphate forms.

recalculated into the molar scale of salt concentrations, but makes it possible to trace the nature of changes in the process parameters. It should also be appreciated that such control devices are standard for almost all water treatment and purification systems.

Figures 3-5 show data on changes in the main process parameters during comparative tests of the considered processing systems.

The behavior of the hyperfiltration element under the considered conditions fully fits into the framework of the existing ideas (Shvedov et al. 1963).

The high membrane selectivity to ionic impurities leads to systematic accumulation of all components in the solution feeding the membrane apparatus, thus reducing the filtration driving force and the membrane permeability. With a constant flow of the solution entering the apparatus, this leads to an increase in the load on the controller, which causes an increase in the brine chamber pressure, partially compensating for the changed osmotic pressure effects. The result is a smooth decrease in the membrane permeability in the process of treating technogenic waters with the accumulation of soluble components.

It can be assumed that, in this salt concentration range, the membrane selectivity is constant. Consequently, the accumulation of alkali metal salts in the circulating solution leads to an increase in the rate of ion mass transfer through the separating membrane, which, at sufficiently high concentrations of electrolytes, begins to slow down the permeability decrease rate (see Fig. 3).

In this regard, the introduction of complexonates to stabilize the condition of alkaline-earth and non-ferrous metals will necessarily lead to a performance degradation in the treatment process. Thus, the reaction of complex formation with polyphosphate ions and other complexones takes place in an equimolar ratio and can be represented by the net equation

$$
\mathrm{Me}^{z^{+}}+\mathrm{Na}_{2} \mathrm{~L} \rightarrow \mathrm{MeL}+2 \mathrm{Na}^{+}
$$

Thus, the binding of one mole of osmotically active doubly and triply charged cations leads to the formation 


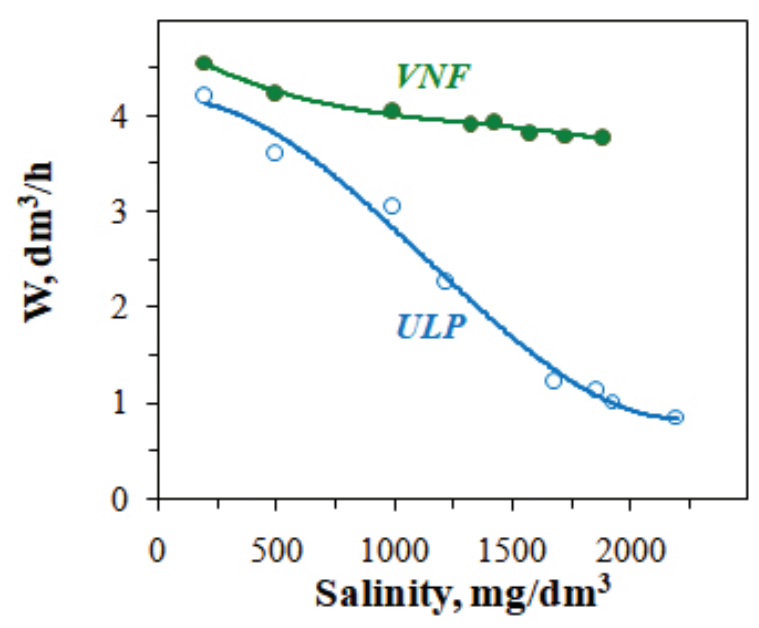

Figure 3. Changes in the membrane permeability $(W)$ depending on the feed solution salinity.

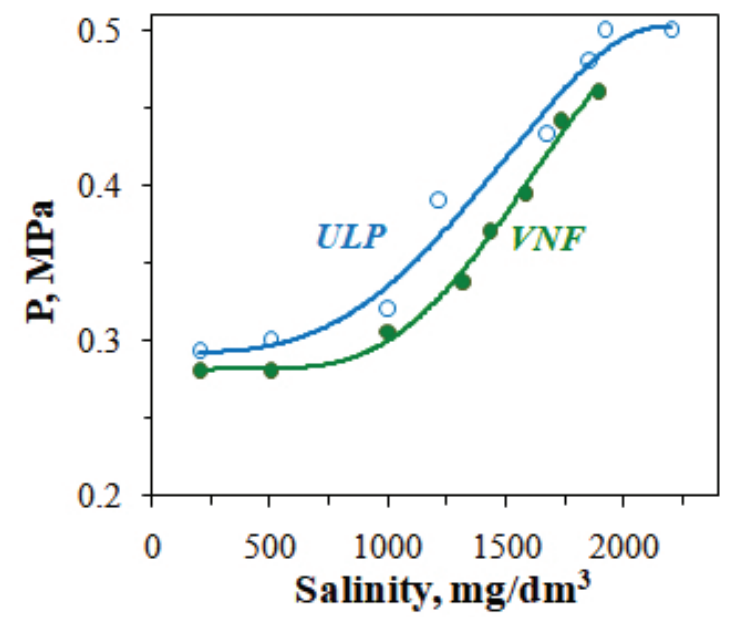

Figure 4. Changes in the brine chamber working pressure $(P)$ depending on the feed solution salinity.

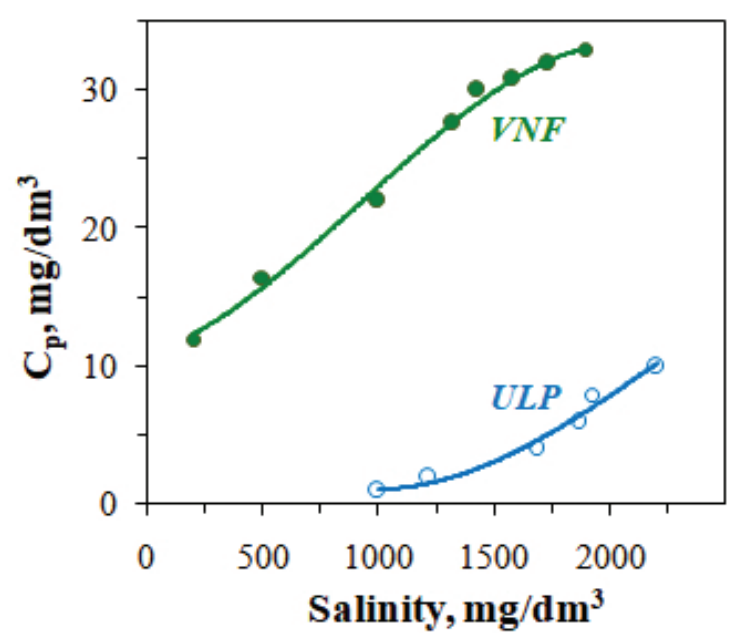

Figure 5. Changes in the permeate salinity $\left(C_{p}\right)$ depending on the feed solution salinity. of three moles of osmotically active particles and, therefore, a threefold increase in osmotic pressure.

Other trends are observed in a system with a nanofiltration membrane. Salt concentrations in the permeate of these devices significantly exceed this figure not only for hyperfiltration but also for the feed solution at this processing stage. This indicates that sodium salts formed during complexation are removed from the concentrate. Thus, osmotically active particles are predominantly complexonates, in relation to which the hyperfiltration membrane exhibits semi-permeable properties.

In the permeates of the systems studied, analytically significant concentrations of alkaline-earth and non-ferrous metals were not observed: this is indicative of complex compounds formed in the solution. In relation to these compounds, the nanofiltration membrane has a high (not less than $99.9 \%$ ) selectivity with practically insignificant retention potential for alkali metal salts. Obviously, during the processing of radioactive solutions, the concentrate discharged from this processing stage must contain ${ }^{134,137} \mathrm{Cs}$ radionuclides. Methods for deep purification of alkali metal salt solutions from these compounds are well known and technically developed (Vasilenko et al. 2005, Ryabchikov 2008, Shvedov et al. 1963, Ivanova and Shvedov 1963, Sharygin et al. 1997, Sharygin and Muromsky 2004, Savkin 2011, Nechaev et al. 2010)

Thus, the nanofiltration unit is able to provide conditions for minimizing the amount of radioactive waste subject to permanent disposal.

To install the third purification stage for obtaining water with a quality exceeding the quality determined by GOST 6709-72 for distilled water is advisable only to obtain high-purity water. At a pressure of $0.5 \mathrm{MPa}$, the degree of conversion of the solution dispensed from the separation unit was $85-90 \%$, with a membrane selectivity of at least $99.8 \%$. In this case, a tenfold increase in specific activity of ${ }^{137} \mathrm{Cs}$ to be discharged to the concentrate hydrographic network will be observed. To ensure the regulatory requirements, it is advisable to direct this solution to the filter-guarantor of the nanofiltration apparatus.

\section{Conclusion}

The obtained data show that, using systems based on industrially manufactured nanofiltration apparatus in combination with widely available and fairly inexpensive complexones, it is possible to solve the main problem of ensuring their deep purification, i.e., fractionation of liquid radioactive waste. The availability of an industrially developed element base could significantly contribute to the creation of cost-effective and environmentally friendly systems for processing technologically and radioactively contaminated waters, including those containing technogenic and natural ligands that complicate the organization of sorption purification systems (Vinnitsky et al. 2016).

The results were obtained in the implementation of the Draft State Task of the Ministry of Education and Science of the Russian Federation in the field of scientific activity No. 13.6572.2017/8.9. 


\section{References}

- Ambashta RD, Sillanpaa MET (2012) Membrane purification in radioactive waste management: a short review. Journal of Environmental Radioactivity 105: 76-84. https://doi.org/10.1016/j.jenvrad.2011.12.002

- Arzhanova EB, Gladush MG, Panteleev AA, Ryabchikov BE (2010) Separation of mono- and polyvalent ions by the method of nanofiltration in aqueous solutions of high concentration. Perspektivnye materially [Advanced materials] 8: 183-188. [in Russian]

- Dytnersky YuI (1986) Baromembrane processes. Theory and estimation. Khimiya Publ., Moscow, 272 pp. [in Russian]

- Ivanova LM, Shvedov VP (1963) Isolation of radioactive cesium from sea water. II. Isolation of cesium in the form of compounds with ferrocyanides of alkaline earth elements. Radiokhimiya 5(2): 185-189.

- Lurie YuYu (1973) Standardized methods for water analysis. Khimiya Publ., Moscow, 376 pp. [in Russian]

- Nechaev AF, Chugunov AS, Stepanov EA (2010) Modernization of technological platform for deep processing of radioactive wastes. Bulletin of SPbGTI(TU) 8(34): 66-70.

- Nikitin VD, Jakimets EM, Timakova NA, Radko VA, Shabashova NV, Tribunsky VV (1963) Preparation of chelate compounds of ethylenediaminetetraacetic acid with cations of some metals and methods for their analysis. Proceedings of S.M. Kirov Ural Polytechnic Institute. "The use of Trilon B in analyzing non-ferrous alloys". Sverdlovsk: 94-103. [in Russian]

- NR-093-14 (2015) Criteria for acceptability of radioactive waste for disposal. Yadernaya i radiatsionnaya bezopasnost 3(77): 59-82.

- Pabby AK (2008) Membrane techniques for treatment in nuclear waste processing: global experience. Membrane Technology 11: 9-13. https://doi.org/10.1016/S0958-2118(08)70233-7
- Ryabchikov BE (2008) Decontamination of Liquid Radioactive Waste. DeLi print Publ., Moscow, 515 pp. [in Russian]

- Savkin AE (2011) Development and trials of a technology for reprocessing of NPP liquid radioactive wastes. Radiokhimiya 53(5): 555-558. https://doi.org/10.1134/S1066362211050195

- Sharygin LM, Muromsky AY (2004) Inorganic sorbent for selective treatment of liquid radioactive wastes. Radiokhimiya 46(2): 185189. https://doi.org/10.1023/B:RACH.0000024949.11280.15

- Sharygin LM, Muromsky AYu, Moiseev VE, Tsekh AR, Vaver AV (1997) Sorption purification of liquid radioactive wastes from nuclear power plants. Atomic Energy 83(1): 493-499. https://doi. org/10.1007/BF02418974

- Shvedov VP, Ivanova LM, Zharikov VI (1963) Isolation of radioactive cesium from sea water. I. Isolation of cesium in the form of compounds with ferrocyanides of zinc, copper and nickel. Radiokhimiya 5(2): 182-185.

- Vasilenko VA, Yefimov AA, Yepimakhov VN, Konstantinov YeA, Stepanov AI, Stepanov IK (2005) The Management of Radioactive Waste in Russia and Countries with Developed Nuclear Power. Morintekh Publ., St Petersburg 304 pp. [in Russian]

- Vinnitsky VA, Nechaev AV, Chugunov AS (2016) Role of simple anionic ligands in deep decontamination of liquid radioactive waste. Radiokhimiya 5(3): 311-316. https://doi.org/10.1134/ S1066362216030140

- Zakrzewska-Trznadel G, Harasimowicz M, Chmielewski AG (2001) Membrane processes in nuclear technology-application for liquid radioactive waste treatment. Separation and Purification Technology 22-23: 617-625. https://doi.org/10.1016/S1383-5866(00)00167-2

- Zhdanov YuF (1979) Chemistry and Technology of Polyphosphates. Khimiya Publ., Moscow, 240 pp. [in Russian] 